\title{
Phytochemicals and antioxidant activity of different parts of bambangan (Mangifera pajang) and tarap (Artocarpus odoratissimus)
}

\begin{abstract}
Mangifera pajang (family: Anacardiaceae; local name: bambangan) and Artocarpus odoratissimus (familiy: Moraceae; local name: tarap) are popular edible fruits in Sabah, Malaysia. The flesh, kernel and peel from M. pajang; seed and flesh from A. odoratissimus were analysed for total antioxidant activity, total polyphenol, total flavonoid and total anthocyanins contents. M. pajang kernel extract displayed the highest free radical scavenging and ferric reducing activities. Total phenolic content of the samples were in the range of 5.96ï $103.3 \mathrm{mg}$ gallic acid equivalent/g. M. pajang kernel and M. pajang flesh contained the highest and lowest total flavonoid content with the values of 10.98 and $0.07 \mathrm{mg}$ rutin equivalent/g, respectively. The antioxidant activities of extracts were significantly correlated with the total phenolic and flavonoid content (but not the anthocyanins content). The phytochemicals and antioxidant properties of M. pajang and A. odoratissimus, especially their by-products (kernel/seed), indicate that they may impart health benefits when consumed and should be regarded as a valuable source of antioxidant-rich nutraceuticals.
\end{abstract}

Keyword: M. pajang; A. odoratissimus; Antioxidant activity; Total phenolic; Total flavonoid 